\title{
Considering renal risk while managing cancer
}

This article was published in the following Dove Press journal:

Cancer Management and Research

16 May 2017

Number of times this article has been viewed

\section{Vahakn B Shahinian' \\ Amit Bahl ${ }^{2}$ \\ Daniela Niepel ${ }^{3}$ \\ Vito Lorusso ${ }^{4}$}

'Department of Internal Medicine, Kidney Epidemiology and Cost Center, University of Michigan, Ann Arbor, MI, USA; ${ }^{2}$ Bristol Haematology and Oncology Centre, University Hospitals Bristol, Bristol, UK; ${ }^{3}$ Medical Development, Amgen (Europe) $\mathrm{GmbH}$, Vienna, Austria; ${ }^{4}$ Medical Oncology Unit, National Cancer Research Centre, Istituto Tumori Giovanni Paolo II, Bari, Italy
Correspondence: Vahakn B Shahinian Department of Internal Medicine, Kidney Epidemiology and Cost Center, University of Michigan, I4I5 Washington Heights, SPH Building I, Suite 3645, Ann Arbor, MI 48I09, USA

Tel +I 73476366 II

Emailvahakn@med.umich.edu
Abstract: Renal function is an important consideration in the management of patients with advanced cancer. There is a reciprocal relationship between cancer and the kidney: chronic kidney disease can increase the risk of developing cancer, and patients with cancer often experience renal impairment owing to age, disease-related factors and nephrotoxic treatments. As therapies for cancer continue to improve, patients are living longer with their disease, potentially extending the period over which they are susceptible to long-term complications. Furthermore, secondary symptoms, such as bone metastases or infections, may arise that will require treatment. Certain treatments, including chemotherapy, antibiotics and some bone-targeted agents, are nephrotoxic and may require dose modifications or interruptions to prevent renal injury. Nephrologists should play a key role in the identification and management of renal impairment in patients with cancer. Furthermore, they may be able to provide advice on protecting the kidneys in instances where nephrotoxic agents require dose reductions or interruptions, and when novel therapies or combinations are used. Collaboration between oncologists and nephrologists is important to optimal patient management. This article reviews the relationship between cancer and kidney disease and examines the treatments that may impact kidney function. Considerations for monitoring renal function are also discussed.

Keywords: advanced cancer, cancer management, elderly, kidney disease, nephrotoxicity, renal function

\section{Introduction}

Advances in health care and treatment options have increased survival times for patients with different solid tumor types. In the UK and the USA, patients with prostate and breast cancer have an estimated 5-year relative survival rate of $28 \%-100 \% 1,2$ and $22 \%-100 \%,{ }^{3,4}$ respectively, depending on the disease stage at diagnosis. Although the relative survival rate of patients with lung cancer is less than that of those with breast or prostate cancer, up to $49 \%$ will survive for 5 years or more..$^{5-7}$ The consequences of improved survival include the increased incidence of complications associated with the disease process, such as bone metastases, ${ }^{8-11}$ and adverse events that may arise as a result of long-term cancer treatments, ${ }^{12,13}$ all of which may increase the risk of renal injury. Kidney function is, therefore, an important consideration when cancer is present, and understanding the connection between the two is important for the optimal disease management. Here, we review the relationship between cancer and kidney disease, and examine the treatments that may impact kidney function. Considerations for monitoring renal function are also discussed. 


\section{Cancer and kidney disease}

Kidney disease frequently coexists with advanced cancer because of their shared risk factors and bidirectional causal mechanisms. The reciprocal relationship between cancer and kidney disease is summarized in Figure 1 and discussed in detail in the following section.$^{14-16}$

\section{Diagnosis of kidney disease}

Chronic kidney disease (CKD) is usually asymptomatic in the early stages, but can be detected using laboratory tests. Kidney function is commonly assessed by means of the estimated glomerular filtration rate (eGFR). Measurement of serum creatinine levels, in combination with age, sex, weight or race, is used to calculate eGFR. The formal definition of CKD requires the presence of a reduced eGFR of $<60 \mathrm{~mL} / \mathrm{min}$ per $1.73 \mathrm{~m}^{2}$ for at least 90 days. ${ }^{17}$ Frequently in the clinical setting, however, a reduced eGFR may be noted on one occurrence without knowledge of its duration - we, hereafter, refer to this as renal impairment (RI), to denote a single reading of eGFR of $<60 \mathrm{~mL} / \mathrm{min}$ per $1.73 \mathrm{~m}^{2}$, without designation of its chronicity. ${ }^{18-20}$

Two equations are routinely used for the estimation of eGFR based on serum creatinine levels: the Modification of Diet in Renal Disease (MDRD) equation and the recently developed Chronic Kidney Disease Epidemiology Collaboration (CKD-EPI) equation, which may be more accurate than the MDRD equation (Table 1). ${ }^{20,21}$ These equations are suitable for use in a broad patient population, including elderly individuals. The Kidney Disease: Improving Global Outcomes (KDIGO) working group does not recommend using one single equation for estimation of renal function, although it recognizes that the CKD-EPI equation may be more precise at higher GFRs and may, therefore, be more applicable than the MDRD equation for day-to-day practice. ${ }^{18}$ Historically, creatinine clearance $(\mathrm{CrCl})$ has been used as a marker of GFR and is determined from serum creatinine and urine creatinine levels. ${ }^{18}$ Current product labeling guidance from the US Food and Drug Administration (FDA) for studies of patients with impaired renal function states that dose adjustment categories can be described based on $\mathrm{CrCl}$ or eGFR. ${ }^{22}$

Measurement of eGFR alone may be insufficient to determine kidney function because there is often a discrepancy between serum creatinine levels and the $\mathrm{CrCl}$ rate, and it should, therefore, be used in conjunction with other renal assessments. ${ }^{23,24}$ In patients with low body mass index $\left(<18.5 \mathrm{~kg} / \mathrm{m}^{2}\right)$, such as cachectic patients with cancer, alternative approaches may be used to provide reliable estimates

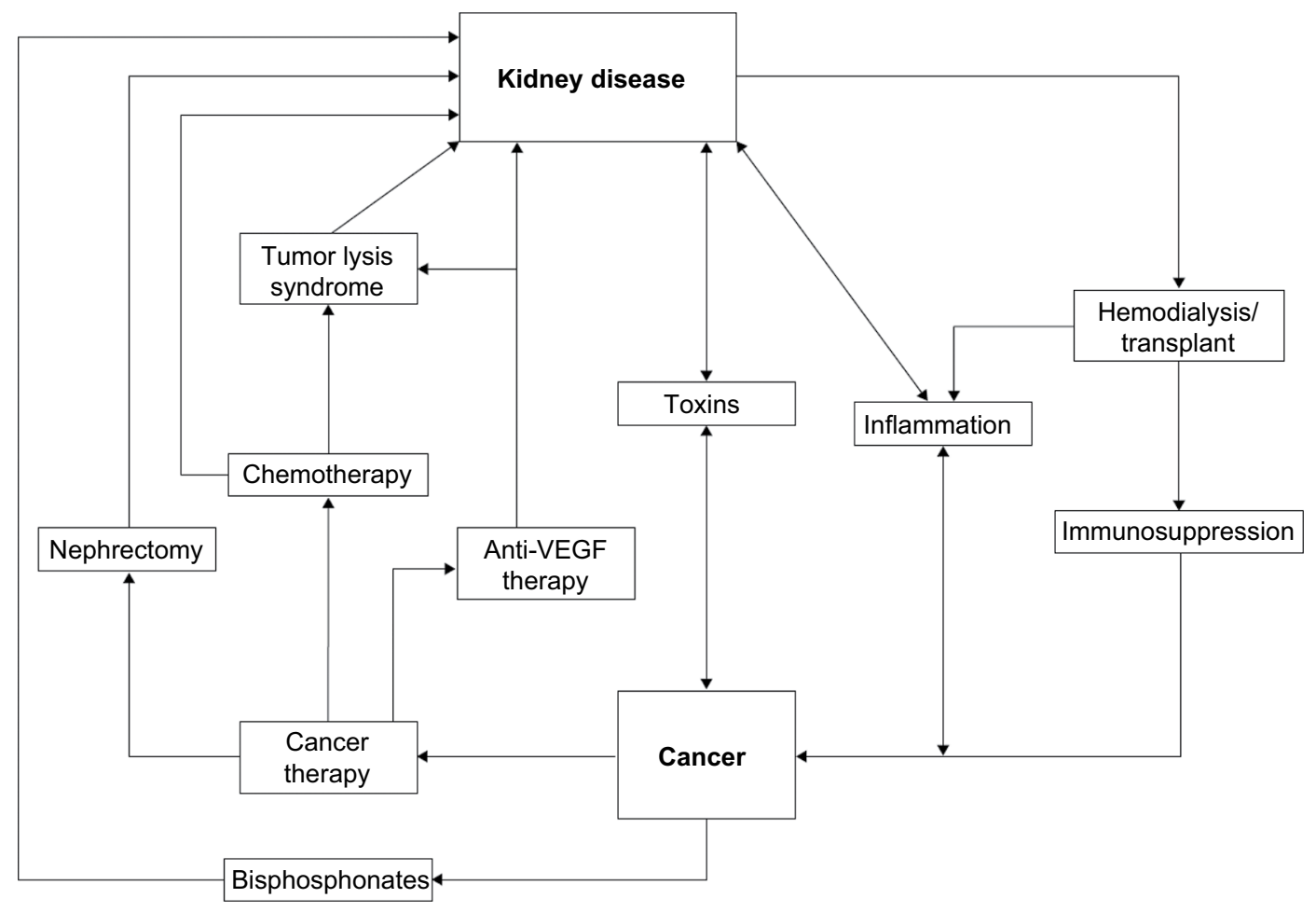

Figure I The reciprocal relationship between cancer and kidney disease.

Note: Data from Stengel B, ${ }^{16}$ Akchurin and Kaskel, ${ }^{42}$ and Abudayyeh et al. ${ }^{119}$

Abbreviation: VEGF, vascular endothelial growth factor. 
Table I Equations used to estimate GFR

\begin{tabular}{|c|c|}
\hline Equation & Notes \\
\hline \multicolumn{2}{|l|}{ Creatinine } \\
\hline Cockcroft-Gault ${ }^{19}$ & Does not estimate GFR \\
\hline \multicolumn{2}{|l|}{$\mathrm{CrCl}=(\mid 40-$ age $) \times$ weight $(\mathrm{kg}) / 72 \times \mathrm{SCr}$} \\
\hline \multicolumn{2}{|l|}{$\mathrm{CrCl}=$ creatinine clearance $(\mathrm{mL} / \mathrm{min})$} \\
\hline \multicolumn{2}{|l|}{$\mathrm{SCr}=$ serum creatinine $(\mathrm{mg} / \mathrm{l} 00 \mathrm{~mL})$} \\
\hline CKD-EPI ${ }^{20}$ & Apply correction factor to GFR values for people of African \\
\hline (if female) or I.I59 (if black) & or Afro-Caribbean descent \\
\hline$\kappa=0.7$ (female) or 0.9 (male) & Less biased than MDRD at estimating GFR in those with a \\
\hline$\alpha=-0.329$ (female) or $-0.4 \mathrm{II}$ (male) & GFR $>60 \mathrm{~mL} / \mathrm{min} / \mathrm{l} .73 \mathrm{~m}^{2}$ \\
\hline minimum $=$ minimum $\mathrm{SCr} / \kappa$ or $\mathrm{I}$ & Better than MDRD at estimating GFR in patients aged $\geq 75$ \\
\hline maximum $=$ maximum $\mathrm{SCr} / \kappa$ or $\mathrm{I}$ & years \\
\hline $\mathrm{SCr}=$ serum creatinine $(\mathrm{mg} / \mathrm{dL})$ & $\begin{array}{l}\text { Interpret with caution in patients with extremes of muscle } \\
\text { mass }\end{array}$ \\
\hline MDRD study equation ${ }^{18,20}$ & May overdiagnose chronic kidney disease \\
\hline \multicolumn{2}{|l|}{ (if African-American) } \\
\hline \multicolumn{2}{|l|}{$\mathrm{SCr}=$ serum creatinine $(\mathrm{mg} / \mathrm{dL})$} \\
\hline \multicolumn{2}{|l|}{ Cystatin C } \\
\hline CKD-EPI ${ }^{18}$ & More accurate than eGFR of creatinine \\
\hline 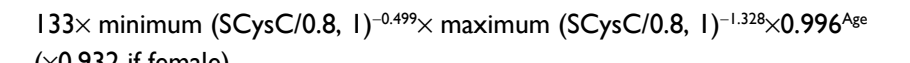 & For confirmatory testing in specific circumstances when eGFR \\
\hline$(\times 0.932$ if female $)$ & based on serum creatinine is less accurate \\
\hline \multicolumn{2}{|l|}{ minimum $=$ minimum $\mathrm{SCys} C / 0.8$ or $\mathrm{I}$} \\
\hline \multicolumn{2}{|l|}{ maximum $=$ maximum $\mathrm{SCys} C / 0.8$ or $\mathrm{I}$} \\
\hline \multicolumn{2}{|l|}{$\mathrm{SCys} C=$ serum cystatin $\mathrm{C}(\mathrm{mg} / \mathrm{L})$} \\
\hline \multicolumn{2}{|l|}{ Creatinine-cystatin C } \\
\hline CKD-EPI'18 & More accurate than equations using creatinine or cystatin $C$ \\
\hline $\mathrm{I} 35 \times$ minimum $(\mathrm{SCr} / \kappa, \mathrm{I})^{\alpha} \times$ maximum $(\mathrm{SCr} / \kappa, \mathrm{I})^{-0.601} \times$ minimum & separately \\
\hline \multicolumn{2}{|l|}{$(\mathrm{SCysC} / 0.8, \mathrm{I})^{-0.375} \times$ maximum $(\mathrm{SCysC} / 0.8, \mathrm{I})^{-0.711} \times 0.995^{\mathrm{Age}} \times 0.969$ (if female) } \\
\hline \multicolumn{2}{|l|}{ or $\times 1.08$ [if black] } \\
\hline \multicolumn{2}{|l|}{$\kappa=0.7$ (female) or 0.9 (male) } \\
\hline \multicolumn{2}{|l|}{$\alpha=-0.248$ (female) or -0.207 (male) } \\
\hline \multicolumn{2}{|l|}{ minimum $(\mathrm{SCr} / \kappa, \mathrm{I})=$ minimum $\mathrm{SCr} / \kappa$ or $\mathrm{I}$} \\
\hline \multicolumn{2}{|l|}{$\operatorname{maximum}(\mathrm{SCr} / \kappa, \mathrm{I})=$ maximum $\mathrm{SCr} / \kappa$ or $\mathrm{I}$} \\
\hline \multicolumn{2}{|l|}{ minimum $(\mathrm{SCys} / 0.8, \mathrm{I})=$ minimum $\mathrm{SCys} C / 0.8$ or $\mathrm{I}$} \\
\hline \multicolumn{2}{|l|}{ maximum $(\mathrm{SCys} C / 0.8, \mathrm{I})=$ maximum $\mathrm{SCys} C / 0.8$ or $\mathrm{I}$} \\
\hline \multicolumn{2}{|l|}{$\mathrm{SCr}=$ serum creatinine $(\mathrm{mg} / \mathrm{dL})$} \\
\hline SCys $\mathrm{C}=$ serum cystatin $\mathrm{C}(\mathrm{mg} / \mathrm{L})$ & \\
\hline
\end{tabular}

Abbreviations: CKD-EPI, Chronic Kidney Disease Epidemiology Collaboration; $\mathrm{CrCl}$, creatinine clearance; eGFR, estimated glomerular filtration rate; GFR, glomerular filtration rate; MDRD, Modification of Diet in Renal Disease; SCr, serum creatinine; SCysC, serum cystatin C.

of renal function; for instance, urine $\mathrm{CrCl}$ measured over a 24-hour period or cystatin-based measurements. ${ }^{21}$ Cystatin $\mathrm{C}$ level can be used to estimate GFR; a meta-analysis found it to be superior to using serum creatinine level for this purpose. ${ }^{25}$ Although cystatin $\mathrm{C}$ measurement may offer some advantages over serum creatinine-based evaluations, the assay can be costly and there is a potential lack of standardization across laboratories. Therefore, the KDIGO working group does not currently recommend use of this assay over serum creatinine-based methods. ${ }^{18}$

Beyond reduction in eGFR, symptoms of kidney disease can include proteinuria, hematuria or albuminuria, or renal tubular abnormalities leading to electrolyte wasting, all of which can be detected using laboratory tests. ${ }^{17}$

\section{Risk factors in common for kidney disease and cancer}

Age is a major risk factor for kidney disease. Decline of renal function is common in the elderly general population; by the age of 70 years, renal function may have declined by up to $40 \% .{ }^{26}$ More than a third of individuals in the healthy population aged over 70 years have moderately impaired renal function. ${ }^{27}$ The physiological changes associated with aging, including diminished renal mass, reduction in renal 
blood flow and loss of nephron function, ${ }^{28}$ contribute toward decreased renal activity. Furthermore, as individuals age, they are likely to acquire an increasing number of comorbidities. ${ }^{29}$ Thus, it is unsurprising that patients with cancer, who are often elderly, may have some degree of RI..$^{30,31}$ In the French Renal Insufficiency and Anticancer Medications (IRMA) national, retrospective, observational study of patients with solid tumors, there was a high incidence of RI $(65.2 \%)$ in a group of 1553 patients aged $\geq 65$ years. ${ }^{31}$ The prevalence of RI increased with age (65-74 years, $61.7 \%$; 75-84 years, $74.7 \%) .{ }^{31} \mathrm{RI}$ occurred frequently in a retrospective study of 11,809 USA patients with bone metastases from solid tumors (mean age 66.9 years); the 5-year prevalence of RI was $43 \%{ }^{32}$ In a retrospective study of elderly Brazilian patients (aged $>65$ years) with solid tumors, $66 \%$ were found to have abnormal renal function. ${ }^{30}$

Type II diabetes mellitus is one of the most common causes of kidney disease in the USA and is itself a risk factor for several types of cancer. ${ }^{15}$ The association between diabetes and cancer is further complicated by the fact that the majority of patients with diabetes are overweight or obese, ${ }^{14}$ which increases their risk of developing several different cancer types ${ }^{33}$ and kidney disease. ${ }^{34}$ Other identified risk factors for CKD include physical inactivity, ${ }^{35}$ smoking, hypertension, ${ }^{36}$ cardiovascular disease and being male, ${ }^{34}$ all of which pose an increased risk of developing certain cancers. ${ }^{15}$

\section{CKD as a risk factor for cancer}

The relationship between cancer and kidney function encompasses more than age and comorbidities (Figure 1). There is an increased risk of certain cancers in individuals with $\mathrm{CKD},{ }^{16}$ and the association is most commonly observed in those with renal cell carcinoma or urothelial cancers. ${ }^{37}$ Patients receiving renal replacement therapies, such as dialysis ${ }^{16,38}$ or transplantation, ${ }^{16,39}$ also have an increased risk of developing cancer. In the UK in 2010, cancer was the most common cause of death in patients who had been given a kidney transplant $(23 \%) .{ }^{40}$ Immunosuppression may contribute to an increased risk of cancer, which can be caused by pre- or posttransplantation treatment with immunosuppressants, ${ }^{41}$ or by endogenous immunosuppression owing to uremia.

The underlying mechanisms for the association between kidney disease and cancer are not well understood and may be multifactorial. However, CKD can cause an inflammatory microenvironment ${ }^{42}$ that may encourage cancer development. Albuminuria, which frequently accompanies inflammatory states, is itself associated with an increased incidence of cancer, in particular urothelial or lung cancer, independent of renal function. ${ }^{43}$ Vitamin D deficiency is highly prevalent among people with moderately reduced kidney function and, in the general population, has been associated with the risk of developing breast, colon and prostate cancer. The mechanisms to explain this association are, however, yet to be elucidated. ${ }^{44}$

\section{Cancer as a cause of kidney disease}

The natural history of cancer may lead to kidney disease via various mechanisms. Acute kidney injury is common in patients with tumors of the kidney or liver, and in those with multiple myeloma, ${ }^{45}$ and can be caused by intravascular volume depletion due to sepsis, vomiting or diarrhea, toxins or accumulation of M-protein in multiple myeloma. ${ }^{46}$ Physical obstruction of the bladder or urethra, often observed in patients with tumors of the bladder, uterus, prostate and cervix, can also result in acute kidney injury. ${ }^{46}$ Nephrotic syndrome may be caused by the invasion of the glomeruli by cancerous cells. ${ }^{47}$ Another complication of cancer is tumor lysis syndrome, which results in metabolic disruption and can be caused by rapid tumor cell turnover, or because of chemotherapy-induced cell lysis. ${ }^{48}$ Cellular release of metabolites, such as potassium, phosphate and citric acid, can lead to the deposition of uric acid and calcium phosphate in the renal tubules, causing acute renal failure, a condition that is further exacerbated in cases of concomitant intravascular volume depletion. ${ }^{48}$

Patients with advanced cancer often develop bone metastases, particularly those with lung, breast and prostate cancer. Bone metastases disrupt normal bone turnover and can cause an imbalance in calcium levels resulting in hypercalcemia of malignancy, affecting $10 \%-30 \%$ of patients with cancer. ${ }^{49}$ Prolonged elevated calcium can cause kidney damage and untreated severe hypercalcemia of malignancy can be fatal. ${ }^{49}$

Hypercalcemia is a key criterion for the diagnosis of multiple myeloma. ${ }^{50}$ It is caused by tumor-induced bone destruction and the formation of bone lesions, which together contribute to elevated calcium levels. ${ }^{51}$ Furthermore, the clonal expansion of plasma cells and subsequent excessive production of immunoglobulin light chains can cause cast nephropathy, further damaging the kidney. ${ }^{52}$

Given that RI is common in patients with advanced cancer, oncologists need to be aware that certain cancer treatments affect the kidney. ${ }^{13}$ These are discussed in detail in the following section.

\section{Prevalence of kidney disease in advanced cancer}

The USA database study found that the 5-year prevalence of RI in patients with solid tumors and bone metastases was 
$43 \%$, and up to $71 \%$ in those with CKD. ${ }^{32}$ In the large IRMA study of 4684 patients with a range of solid tumors, over half of patients with breast, prostate or lung cancer had abnormal renal function. ${ }^{53-55}$ Renal failure can occur in patients with advanced cancer, affecting $0.4 \%$ of women with breast cancer and bone metastases. ${ }^{55}$ This is more common in patients with prostate cancer, with one database study reporting that $12 \%$ of men with prostate cancer had renal failure in the final year of life. ${ }^{56}$

\section{Considering renal risk while managing cancer}

\section{Assessing renal risk in patients with cancer}

It is reasonable to evaluate renal function in all patients with cancer ${ }^{23,24,57}$ because RI has been detected in almost two-thirds of patients with cancer who have normal serum creatinine levels. ${ }^{24}$ Given that kidney disease is common in patients with cancer, it is important to understand a patient's renal function in order to assess the risk of further kidney injury that could occur owing to the nephrotoxic effects of some cancer treatments.

Guidelines recommend regular renal monitoring for patients receiving potential nephrotoxic agents. ${ }^{18,23,58,59}$ For elderly patients with cancer, the International Society of Geriatric Oncology recommends that renal function should be assessed and hydration should be optimized before drug treatment. ${ }^{23}$ The IRMA investigators recommend that $\mathrm{CrCl}$ is calculated for patients who are receiving nephrotoxic drugs that require dose adjustments in order that their dosage is prescribed according to patients' levels of renal function. These patients should receive adequate hydration and be monitored closely for a decline in renal function. ${ }^{23,24}$ The use of antiresorptive therapies for the management of bone metastases is discussed in detail in the following section.

\section{Nephrotoxicity associated with the management of cancer Diagnosis}

Imaging is often used to locate tumors or in the assessment of disease stage. Computed tomography (CT) is the preferred method for identifying renal cell carcinoma and metastases, but is associated with a risk of contrast-induced acute kidney injury, caused by the use of iodinated contrast medium. ${ }^{60}$ The incidence of kidney injury in this setting is low in the general population (2\%); however, in patients with risk factors for kidney disease it increases up to $50 \% .{ }^{60}$ Magnetic resonance imaging is often used to detect tumors; although it is less toxic than $\mathrm{CT}$ it also carries a potential risk of kidney injury owing to the use of contrast media often containing gadolinium. ${ }^{61}$ Therefore, before renal imaging, physicians should consider a patient's baseline risk of kidney injury and should use prophylaxis with intravenous fluids as an effective intervention. In addition, physicians should consider the use of prophylactic $N$-acetylcysteine, an agent that has been shown to prevent radiocontrast-induced nephropathy. ${ }^{60}$

\section{Chemotherapy}

Most commonly used chemotherapies are excreted through the kidneys and have known nephrotoxicity. ${ }^{62}$ Cisplatin is a major antineoplastic alkylating agent used for the treatment of solid tumors. However, acute kidney injury has been reported in $20 \%-30 \%$ of patients receiving cisplatin therapy. ${ }^{63}$ The nephrotoxicity associated with cisplatin increases in a dose-dependent fashion ${ }^{64}$ and may be managed with amifostine, an agent that protects tissue from chemotherapyinduced damage ${ }^{65}$ Other alkylating agents such as ifosfamide and cyclophosphamide are also nephrotoxic and may have long-term renal effects. For example, survivors of childhood cancers had significantly lower eGFRs in adulthood if they had received high-dose cisplatin ( 83 vs $101, p=0.004$ ) or high-dose ifosfamide ( 88 vs $98, p=0.02$ ) than those who had not received such treatments. ${ }^{66}$ Ifosfamide treatment of solid tumors is also associated with long-term nephrotoxicity in adults. ${ }^{67}$ Ifosfamide can enter the kidney tubules via organic cation transporters and cause proximal tubular injury. Chloracetaldehyde is a toxic metabolite of ifosfamide that injures kidney tissue. ${ }^{62}$ Owing to differences in metabolism, cyclophosphamide treatment produces much less chloracetaldehyde and is therefore substantially less nephrotoxic than ifosfamide, although another metabolite, acrolein, can lead to urotoxicity with hemorrhagic cystitis. ${ }^{62}$ Beyond those issues, cyclophosphamide has also been rarely associated with the syndrome of inappropriate antidiuresis hormone secretion (SIADH) ${ }^{62,68}$ The mechanism of action of cyclophosphamide-related SIADH has not been determined, but it may be caused by a direct toxic effect of cyclophosphamide or its metabolites on renal collecting tubules, or an antidiuretic hormone-like activity of cyclophosphamide metabolites. ${ }^{68}$

Methotrexate is another widely used chemotherapy that is associated with nephrotoxicity. ${ }^{32}$ Indeed, up to $12 \%$ of patients who received high-dose methotrexate for the treatment of various cancers have experienced acute kidney injury. ${ }^{62}$ Furthermore, renal injury can impair clearance of methotrexate, leading to accumulation and further toxicity. Toxicity may be managed using the tissue-protectants leucovorin, or carboxypeptidase-G2, or hemodialysis. ${ }^{69}$ 
Melphalan is often administered to patients with multiple myeloma, a disease often associated with RI. ${ }^{70}$ Melphalan clearance may be decreased in patients with RI and subsequent progression from RI to renal failure has been reported in a patient receiving treatment for multiple myeloma. ${ }^{71}$ Dose reductions of $50 \%$ are recommended for patients with moderate $\mathrm{RI}(\mathrm{CrCl} 30-50 \mathrm{~mL} / \mathrm{min}$ ) who are not scheduled to receive hematopoietic stem cell transplantation (HSCT), but it should not be used in patients with more severe $\mathrm{RI}(\mathrm{CrCl}$ $<30 \mathrm{~mL} / \mathrm{min}$; Table 2). ${ }^{72}$ Nonetheless, high-dose melphalan with HSCT has been used successfully in patients with endstage renal failure who are receiving dialysis. ${ }^{72,73}$

\section{Antivascular endothelial growth factor receptor therapies}

The use of agents that target the vascular endothelial growth factor (VEGF) pathway is increasing in the treatment of certain solid tumors, including renal cell carcinoma, nonsmall cell lung cancer, gastrointestinal stromal tumors and colorectal cancer. ${ }^{74}$ The humanized monoclonal antibody bevacizumab was one of the first VEGF inhibitors to be used in clinical practice for the treatment of solid tumors, but its use is associated with a significantly increased risk of proteinuria and hypertension. ${ }^{75}$ In a phase 4 , open-label study in patients with lung cancer, grade 3 or higher proteinuria was reported in $3 \%$ of patients and hypertension was reported in $6 \%$ of patients who received bevacizumab. ${ }^{76}$ Other VEGF receptor targets, such as the tyrosine kinase inhibitors sorafenib, sunitinib and pazopanib, are used for the treatment of patients with cancer, but are associated with similar adverse vascular effects. ${ }^{74}$ A meta-analysis of 16 clinical trials of patients with solid tumors has shown that the risk of developing proteinuria was $41 \%$ higher with the human recombinant fusion protein aflibercept compared with controls; furthermore, this risk was substantially greater with aflibercept than with bevacizumab $(85 \%) .{ }^{77}$

\section{Immuno-oncology therapies}

The immuno-oncology therapies nivolumab and pembrolizumab are monoclonal antibodies that have both recently been approved to treat advanced melanoma. ${ }^{78,79}$ Nivolumab is also approved for the treatment of locally advanced or metastatic nonsmall cell lung cancer after prior chemotherapy and as a monotherapy for the treatment of advanced renal cell carcinoma after prior therapy. ${ }^{78}$ These compounds are currently under investigation in men with prostate cancer. However, in phase 3 studies, the use of nivolumab monotherapy or nivolumab in combination with ipilimumab is associated with immune-related nephritis and renal dysfunction $(3.2 \%$ [55/1728] and 4.2\% [19/448], respectively).$^{78}$ It is therefore recommended that patients should be monitored for signs and symptoms of nephritis or renal dysfunction. Treatment should be withheld for patients with mild-to-moderate renal dysfunction (from $50 \%$ up to $300 \%$ increase from a normal baseline serum creatinine) until normalization, with discontinuation recommended in more severe cases. ${ }^{78}$ Immune-related nephritis has also been reported for a small number of patients in phase 3 studies receiving pembrolizumab (0.4\% [7/1567]); patients should be monitored for changes in renal function, with treatment interrupted or discontinued for indications described above. ${ }^{79}$

\section{Androgen deprivation therapy (ADT)}

ADT is commonly used for the treatment of prostate cancer. However, its use has been associated with an increased risk of acute kidney injury; a large database study calculated an odds ratio of sustaining acute kidney injury of 2.48 (95\% confidence interval, 1.61-3.82) with ADT treatment versus controls. ${ }^{80}$ ADT may cause dyslipidemia or result in metabolic syndrome, all of which can contribute to kidney injury. ${ }^{80}$ Furthermore, patients who received ADT as part of a combination therapy had the highest risk of acute kidney injury, suggesting that ADT may potentiate the nephrotoxicity of other agents. ${ }^{80}$

\section{Antiresorptive therapies}

Bone metastases are common in patients with advanced solid tumors, such as those affecting the breast, prostate or lung $(\sim 70 \%-90 \%$ of patients with these cancers have evidence of metastatic bone disease), ${ }^{11,81}$ therefore patients may require antiresorptive drugs such as bisphosphonates ${ }^{82,83}$ and denosumab, ${ }^{84-87}$ for the prevention of skeletal complications of bone metastases secondary to solid tumors.

The use of the bisphosphonate zoledronic acid $4 \mathrm{mg}$ every 3-4 weeks has been associated with a risk of renal deterioration and, in some rare instances, renal failure. ${ }^{88} \mathrm{How}-$ ever, many patients with kidney disease may be prescribed bisphosphonates, despite the risk of further kidney damage. In a large, retrospective chart review of individuals with bone metastases secondary to solid tumors in the USA, almost half (48\%) of patients received bisphosphonates within 12 months of confirmation of CKD. ${ }^{32}$ Prescribing information stipulates a reduced dose of zoledronic acid for patients with RI and that creatinine monitoring is recommended before each dose. For patients with severe RI, the use of zoledronic acid is not recommended (Table 2). ${ }^{88}$ Despite this, many patients will 
Table 2 Label recommendations for common nephrotoxic agents used in cancer therapy

\begin{tabular}{|c|c|c|}
\hline Drug & Tumor type(s) & Dose adjustment/recommendations \\
\hline \multicolumn{3}{|l|}{ Chemotherapies } \\
\hline $\begin{array}{l}\text { Abiraterone } \\
\text { acetate }^{120}\end{array}$ & $\begin{array}{l}\text { Castration-resistant prostate } \\
\text { cancer }\end{array}$ & $\begin{array}{l}\text { No dose adjustment required for patients with RI. No clinical experience in patients with } \\
\text { severe } \mathrm{RI} \text { and prostate cancer therefore caution is advised }\end{array}$ \\
\hline Cisplatin ${ }^{100}$ & $\begin{array}{l}\text { Testicular, ovarian, bladder } \\
\text { and head and neck cancers }\end{array}$ & $\begin{array}{l}\text { Adequate hydration is required before, during and after infusion for patients with RI, especially } \\
\text { severe RI } \\
\text { Cisplatin is contraindicated in patients with preexisting RI. Nephrotoxicity may be potentiated } \\
\text { by aminoglycoside antibiotics }\end{array}$ \\
\hline Cyclophosphamide ${ }^{101}$ & $\begin{array}{l}\text { Hematological malignancies, } \\
\text { Ewing's sarcoma, } \\
\text { neuroblastoma, ovarian, } \\
\text { breast and small cell lung } \\
\text { cancers }\end{array}$ & $\begin{array}{l}\text { Adequate hydration is required before, during and after administration. Dose reduction of } 50 \% \\
\text { is recommended for patients with GFR }<10 \mathrm{~mL} / \mathrm{min}\end{array}$ \\
\hline Enzalutamide ${ }^{99}$ & $\begin{array}{l}\text { Castration-resistant prostate } \\
\text { cancer }\end{array}$ & $\begin{array}{l}\text { No dose adjustment required for patients with mild or moderate } \mathrm{RI}(\mathrm{CrCl} \geq 30 \mathrm{~mL} / \mathrm{min}) \\
\text { Caution is advised in patients with severe } \mathrm{RI}(\mathrm{CrCl}<30 \mathrm{~mL} / \mathrm{min}) \text { or end-stage renal disease }\end{array}$ \\
\hline Ifosfamide 102 & Wide range of tumor types & $\begin{array}{l}\text { Adequate hydration is required during and after administration } \\
\text { Ifosfamide is contraindicated in patients with preexisting RI } \\
\text { Dose should be determined and adjusted for each individual, and kidney function should be } \\
\text { closely monitored before and after treatment }\end{array}$ \\
\hline Methotrexate $e^{103}$ & Wide range of tumor types & $\begin{array}{l}\text { Adequate hydration is required before, during and after administration. Renal function should } \\
\text { be closely monitored before, during and after treatment. Dose should be reduced if patients } \\
\text { have } \mathrm{RI}(\mathrm{CrCl} 20-50 \mathrm{~mL} / \mathrm{min}) \text { by } 50 \% \text {. Methotrexate is contraindicated in patients with severe } \\
\mathrm{RI}(\mathrm{CrCl}<20 \mathrm{~mL} / \mathrm{min})\end{array}$ \\
\hline Melphalan ${ }^{72}$ & $\begin{array}{l}\text { Ovarian cancer and multiple } \\
\text { myeloma }\end{array}$ & $\begin{array}{l}\text { A } 50 \% \text { dose reduction is required for patients with moderate } \mathrm{RI}(\mathrm{CrCl} 30-50 \mathrm{~mL} / \mathrm{min}) \text { who are } \\
\text { scheduled to receive high-dose melphalan without hematopoietic stem cell rescue. Melphalan } \\
\text { should not be used in patients with severe RI }\end{array}$ \\
\hline \multicolumn{3}{|l|}{ Targeted agents } \\
\hline Axitinib 121 & $\begin{array}{l}\text { Advanced renal cell } \\
\text { carcinoma }\end{array}$ & $\begin{array}{l}\text { No dose adjustment is required } \\
\text { Virtually no data are available regarding axitinib clearance in patients with } \mathrm{CrCl}<15 \mathrm{~mL} / \mathrm{min} \text {. } \\
\text { Axitinib has not been studied in patients with } \mathrm{RI}\end{array}$ \\
\hline Bevacizumab ${ }^{98}$ & $\begin{array}{l}\text { Colorectal, breast, nonsmall } \\
\text { cell lung, renal, ovarian and } \\
\text { cervical cancers }\end{array}$ & $\begin{array}{l}\text { No trials have been conducted to investigate the pharmacokinetics of bevacizumab in patients } \\
\text { with RI because the kidneys are not a major organ for bevacizumab metabolism or excretion. } \\
\text { Discontinuation of drug if adverse events are indicated }\end{array}$ \\
\hline Pazopanib ${ }^{107}$ & $\begin{array}{l}\text { Renal cell carcinoma and soft } \\
\text { tissue sarcoma }\end{array}$ & $\begin{array}{l}\text { No dose adjustment is required with } \mathrm{CrCl}>30 \mathrm{~mL} / \mathrm{min} \\
\text { Caution advised in patients with } \mathrm{CrCl}<30 \mathrm{~mL} / \mathrm{min}\end{array}$ \\
\hline Sunitinib ${ }^{104}$ & $\begin{array}{l}\text { Gastrointestinal stromal } \\
\text { tumor, renal cell } \\
\text { carcinoma and pancreatic } \\
\text { neuroendocrine tumors }\end{array}$ & $\begin{array}{l}\text { No starting dose adjustments required for patients with RI or end-stage renal disease on } \\
\text { dialysis. Subsequent dose adjustments should be based on individual safety and tolerability. } \\
\text { Discontinue treatment in patients with nephrotic syndrome }\end{array}$ \\
\hline Nivolumab $^{78}$ & $\begin{array}{l}\text { Melanoma nonsmall cell lung } \\
\text { cancer and advanced renal } \\
\text { cell carcinoma }\end{array}$ & $\begin{array}{l}\text { No dose adjustment is required for patients with mild or moderate RI } \\
\text { Treatment should be permanently discontinued for patients with grade } 4 \text { creatinine elevation }\end{array}$ \\
\hline Pembrolizumab ${ }^{79}$ & Melanoma & $\begin{array}{l}\text { No dose adjustment is required for patients with mild or moderate RI } \\
\text { Treatment should be permanently discontinued for patients with grade } 3 \text { or } 4 \text { nephritis }\end{array}$ \\
\hline \multicolumn{3}{|c|}{ Bone-targeted agents } \\
\hline Zoledronic acid ${ }^{88}$ & $\begin{array}{l}\text { Advanced malignancies with } \\
\text { bone metastases }\end{array}$ & $\begin{array}{l}\text { Contraindicated in patients with severe } \mathrm{RI}(\mathrm{CrCl}<30 \mathrm{~mL} / \mathrm{min}) \text {. Dose adjustment for patients } \\
\text { with mild-to-moderate } \mathrm{RI} \text { and treatment withheld for renal deterioration. Serum creatinine } \\
\text { should be measured before each dose and daily supplementation with calcium } 500 \mathrm{mg} \text { and } \\
\text { vitamin } \mathrm{D} 400 \mathrm{IU}\end{array}$ \\
\hline \multicolumn{3}{|l|}{ Antibiotics } \\
\hline $\begin{array}{l}\text { Aminoglycosides (e.g., } \\
\text { gentamicin }{ }^{105} \text { and } \\
\left.\text { tobramycin }{ }^{106}\right)\end{array}$ & NA & $\begin{array}{l}\text { Dose reductions according to degree of RI. Should be used with caution in patients with } \\
\text { existing RI. Serum concentration monitoring of gentamicin recommended adjusting the } \\
\text { frequency of dosage according to degree of renal function. Tobramycin should not be used } \\
\text { concomitantly with dialysis }\end{array}$ \\
\hline
\end{tabular}

Abbreviations: $\mathrm{CrCl}$, creatinine clearance; GFR, glomerular filtration rate; IU, international units; NA, not applicable; RI, renal impairment. 
not undergo proper monitoring of renal function during treatment with bisphosphonates. ${ }^{89}$ A study of physicians treating patients with bone metastases secondary to solid tumors found that managing the risk of RI was their primary safety concern, but there appears to be a discrepancy between clinical recommendations and real-world practice. ${ }^{90}$ Treatment with zoledronic acid has been associated with hypocalcemia; some cases have been severe and patients have required hospitalization. ${ }^{88}$ Prescribing information recommends that serum calcium should be measured and hypocalcemia should be corrected before initiating therapy with zoledronic acid. Patients treated with bisphosphonates should be adequately supplemented with calcium and vitamin D to minimize the risk of hypocalcemia. ${ }^{88}$

Pamidronate is another bisphosphonate that is associated with nephrotoxicity. Pamidronate is approved at a dose of 90 $\mathrm{mg}$ to treat osteolytic bone metastases secondary to breast cancer (2-hour infusion every 3-4 weeks) and osteolytic bone lesions associated with multiple myeloma (4-hour infusion once every 4 weeks). ${ }^{91}$ Pamidronate has been associated with nephrotoxic syndrome and focal segmental glomerulosclerosis (FSGS), with multiple cases of FSGS reported in the medical literature. ${ }^{92}$ These nephrotoxic effects appear to be dose-dependent and infusion time-dependent. ${ }^{92}$ The USA label stipulates that single doses of $90 \mathrm{mg}$ should not be exceeded and serum creatinine should be assessed prior to each treatment. Pamidronate should not be used to treat patients with bone metastases who have severe RI. ${ }^{91}$

Denosumab $120 \mathrm{mg}$ monthly is used for the prevention of skeletal-related events in patients with bone metastases..$^{93,94}$ Denosumab is neither excreted through the kidneys nor associated with renal toxicity, so dose adjustment is not required when administered to patients with renal dysfunction..$^{93,94}$ However, label recommendations state that all patients who are prescribed denosumab should receive daily vitamin $\mathrm{D}$ and calcium supplementation, owing to the risk of developing hypocalcemia. ${ }^{93,94}$ This is particularly important for patients with severe $\mathrm{RI}(\mathrm{CrCl}$ of $<30 \mathrm{~mL} / \mathrm{min}$ ) or for individuals receiving dialysis, ${ }^{87}$ and in those for whom regular calcium monitoring is required. ${ }^{93,94}$ This is in line with the European Society for Medical Oncology clinical practice guidelines for managing bone health in patients with cancer. ${ }^{58}$

\section{Nephrotoxic antibiotics}

Patients with cancer, particularly those undergoing chemotherapy, are at increased risk of developing serious infections that are commonly treated using antibiotics. However, the use of certain antibiotics (or combinations of antibiotics) is associated with acute tubular necrosis owing to renal excretion, which can result in cumulative kidney damage. ${ }^{95}$ Antibiotics associated with acute kidney injury include aminoglycosides, penicillins, cephalosporins and fluoroquinolones. Nephrotoxicity can affect up to $50 \%$ of patients receiving these treatments, and the risk of damage increases with advancing age, volume depletion and sepsis. Long treatment courses and high doses of antibiotics can further increase the risk of nephrotoxicity. ${ }^{95}$ Therefore, careful dose adjustments may be required to ensure that the balance between nephrotoxicity and efficacy is maintained.

\section{Dose adjustments or interruptions for optimal patient management}

As discussed, many patients will receive nephrotoxic agents as part of their cancer treatment and may subsequently require dose adjustments to manage kidney-related adverse events. In the large USA study of 11,809 patients with bone metastases secondary to solid tumors, $23.4 \%$ of patients received a nephrotoxic agent prior to diagnosis of bone metastases, rising to $69 \%$ after diagnosis. ${ }^{32}$

Many chemotherapeutic agents are metabolized by the kidney, producing toxic by-products in the process. RI can result in delayed drug excretion and local and systemic toxicity may arise. ${ }^{96}$ Chemotherapy dose adjustments are therefore frequently required when administered to patients with RI. In the IRMA study, most (79.9\%) patients who were given an anticancer drug received at least one agent that required a dosage adjustment or an agent for which no data were available on use in patients with RI. ${ }^{24}$ This affected most patients receiving treatment for prostate cancer $(82.9 \%)^{53}$ or breast cancer $(90.4 \%) .{ }^{55}$ For patients with advanced cancers and bone metastases, dose reductions are recommended in those with mild-to-moderate RI receiving intravenous zoledronic acid ${ }^{88}$ In clinical trials, dose adjustments have been reported in approximately one-fifth of patients receiving zoledronic acid. ${ }^{84,97}$ Common agents used in cancer therapy that require dose adjustments based on renal function are shown in Table $2 .{ }^{88,98-107}$

\section{Mitigating renal complications: role of the nephrologist}

An important aspect of minimizing the risk of renal injury includes early recognition of RI, or even prevention. This can be accomplished by routine use of eGFR estimation rather than serum creatinine alone (which may be in the normal range in older patients or those with muscle wasting) and urine protein assessment to identify patients with preexisting RI, or close monitoring of urine output to detect acute reductions in renal function. These scenarios may dictate a need to 
reduce drug doses, avoid nephrotoxic agents and administer intravenous fluids to correct volume depletion. Perhaps most importantly, early involvement of or routine collaboration with a nephrologist in the care of patients with cancer may improve outcomes.

The nephrologist can assist with proper identification of the presence of preexisting renal disease, or other conditions that put patients at risk of acute kidney injury related to the management of cancer. Acute kidney injury is a common complication among hospitalized patients with cancer and is associated with an increased length of stay and mortality. ${ }^{108,109}$ One example in which early intervention by a nephrologist may help is in the case of tumor lysis syndrome, the consequences of which include RI, cardiac arrhythmia and death. ${ }^{110}$ Patients at risk of this condition can be identified, enabling the use of prophylactic measures, such as intravenous fluids or xanthine oxidase inhibitors. ${ }^{11,112}$ For those with established tumor lysis syndrome, nephrologists can advise on the acceptability of using rasburicase, which helps to clear uric acid from the blood, and in severe cases, of possibly using dialytic therapies.

Another scenario where the assistance of a nephrologist may be beneficial is for the planned administration of potential nephrotoxins, such as intravenous contrast for imaging, certain antibiotics or chemotherapeutic agents. ${ }^{108}$ In these cases, collaboration between the nephrologist and oncologist may help achieve the best possible benefit:risk ratio when using these nephrotoxic agents. Nephrologists can advise on the need for dose reductions and ensure the proper maintenance of adequate volume balance, which can reduce the risk of renal injury across the spectrum of nephrotoxic exposures. ${ }^{96}$ In addition, nephrologists can identify and recommend the discontinuation of discretionary medications that are potentially nephrotoxic. Nonsteroidal antiinflammatory agents, for example, can in a certain risk context result in renal injury, even after a modest number of doses. ${ }^{113,114}$

Finally, nephrologists can play an important role in the diagnosis of renal disease, particularly for rare conditions that are unique to the cancer context, many of which require renal biopsy for the confirmation of the diagnosis. Examples of these include parenchymal invasion of the kidney by tumor cells (usually observed with leukemias or lymphomas), paraneoplastic glomerulonephritides and thrombotic microangiopathies due to certain chemotherapeutic agents, or the cancer itself. ${ }^{115}$

Given the rapidly evolving field of cancer chemotherapeutics, the prevalence of underlying CKD in elderly patients with malignancies, and the broadening range of renal complications secondary to cancers or their treatment, there has been increasing recognition of the need for specialized knowledge in this clinical context. This has resulted in the development of a new subspeciality of onconephrology. ${ }^{116}$ The American Society of Nephrology has established an Onconephrology Forum Group, ${ }^{117}$ and the University of Texas MD Anderson Cancer Center is offering a fellowship training program. ${ }^{118}$

The partnership between nephrologists and oncologists is important for the optimal management of patients; the identification of onconephrology as an independent medical specialty may help enhance this relationship. The development of this speciality and the enhancement of collaboration between experts have the potential for valuable research advances and to encourage guideline preparation on the management of kidney disease in patients with cancer. ${ }^{119}$

\section{Conclusion}

Improvements in cancer therapy mean that patients are surviving for longer periods of time, with a rapidly expanding range of therapeutic options for management of the primary cancer and for its secondary effects such as bone metastases or infections, many of which have the potential for nephrotoxicity. There is, therefore, increasing recognition of the need for attention to kidney disease in the context of cancer. The balance between cancer therapy and preservation of renal function must be considered carefully by physicians treating patients with advanced cancer, with thoughtful choice and dosing of antineoplastic treatments and bone-targeted agents to minimize nephrotoxicity. Collaboration between nephrologists and oncologists may help ensure that care of patients with cancer and kidney disease is optimized.

\section{Acknowledgments}

Medical writing support was provided by Liz Hartfield, $\mathrm{PhD}$, and Sarah Griffiths, PhD, of Oxford PharmaGenesis Ltd, Oxford, UK. Funding for this support was provided by Amgen (Europe) GmbH. Editorial support was provided by Emma Booth and Sarah Petrig of Amgen (Europe) GmbH.

\section{Disclosure}

A Bahl: advisory boards and honorarium from Amgen, Bayer, Jansen, Astellas, Sanofi, Novartis. Research grants from Ipsen, Sanofi. VB Shahinian: received payments for consultations from Amgen. V Lorusso: has no disclosures. D Niepel: is an employee of Amgen (Europe) GmbH, Vienna, Austria, and holds stock. The authors report no other conflicts of interest in this work. 


\section{References}

1. American Cancer Society. 2015. Survival rates for prostate cancer. Available from: http://www.cancer.org/cancer/prostatecancer/ detailedguide/prostate-cancer-survival-rates. Accessed March 16, 2015.

2. Cancer Research UK. 2011. Prostate cancer survival statistics. Available from: http://www.cancerresearchuk.org/cancer-info/cancerstats/ types/prostate/survival/prostate-cancer-survival-statistics. Accessed March 16, 2015.

3. American Cancer Society. 2015. Breast cancer survival by stage. Available from: http://www.cancer.org/cancer/breastcancer/detailedguide/ breast-cancer-survival-by-stage. Accessed March 16, 2015.

4. Cancer Research UK. 2011. Breast cancer survival. Available from: http://www.cancerresearchuk.org/cancer-info/cancerstats/types/breast/ survival/. Accessed March 16, 2015.

5. American Cancer Society. 2015. Non-small cell lung cancer. Available from: http://www.cancer.org/cancer/lungcancer-non-smallcell/ detailedguide/non-small-cell-lung-cancer-survival-rates. Accessed March 16, 2015.

6. American Cancer Society. 2015. Small cell lung cancer. Available from: http://www.cancer.org/cancer/lungcancer-smallcell/detailedguide/ small-cell-lung-cancer-survival-rates. Accessed March 16, 2015.

7. Cancer Research UK. 2011. Lung cancer survival. Available from: http://www.cancerresearchuk.org/cancer-info/cancerstats/types/lung/ survival/. Accessed March 16, 2015.

8. Blum RH, Novetsky D, Shasha D, Fleishman S. The multidisciplinary approach to bone metastases. Oncology (Williston Park). 2003;17(6):845-857; discussion 862-863, 867.

9. Coleman RE. Metastatic bone disease: clinical features, pathophysiology and treatment strategies. Cancer Treat Rev. 2001;27(3):165-176.

10. Coleman RE, Rubens RD. The clinical course of bone metastases from breast cancer. Br J Cancer. 1987;55(1):61-66.

11. Parker C, Nilsson S, Heinrich D, et al. Alpha emitter radium-223 and survival in metastatic prostate cancer. $N$ Engl J Med. 2013;369(3): 213-223.

12. Azim HA Jr, de Azambuja E, Colozza M, Bines J, Piccart MJ. Longterm toxic effects of adjuvant chemotherapy in breast cancer. Ann Oncol. 2011;22(9):1939-1947.

13. Janus N, Launay-Vacher V, Byloos E, et al. Cancer and renal insufficiency results of the BIRMA study. Br J Cancer. 2010;103(12):1815-1821.

14. Centers for Disease Control and Prevention (CDC). Prevalence of overweight and obesity among adults with diagnosed diabetes - United States, 1988-1994 and 1999-2002. MMWR Morb Mortal Wkly Rep. 2004;53(45):1066-1068.

15. Habib SL, Rojna M. Diabetes and risk of cancer. ISRN Oncol. 2013;2013:583786.

16. Stengel B. Chronic kidney disease and cancer: a troubling connection. J Nephrol. 2010;23(3):253-262.

17. NICE. 2015. NICE clinical guideline 182 - Chronic kidney disease: early identification and management of chronic kidney disease in adults in primary and secondary care. Available from: https://www.nice.org. uk/guidance/cg182/resources/guidance-chronic-kidney-disease-pdf. Accessed September 18, 2015.

18. KDIGO. Clinical Practice Guideline for the Evaluation and Management of Chronic Kidney Disease. Kidney Int Suppl. 2013;3(1): 136-150.

19. Cockcroft DW, Gault MH. Prediction of creatinine clearance from serum creatinine. Nephron. 1976;16(1):31-41.

20. Levey AS, Stevens LA, Schmid CH, et al. A new equation to estimate glomerular filtration rate. Ann Intern Med. 2009;150(9):604-612.

21. Aapro M, Launay-Vacher V. Importance of monitoring renal function in patients with cancer. Cancer Treat Rev. 2012;38(3):235-240.

22. US Food and Drug Administration. Guidance for industry. Pharmacokinetics in patients with impaired renal function - study design, data analysis, and impact on dosing and labeling; 2010. Available from: http:// www.fda.gov/downloads/Drugs/GuidanceComplianceRegulatory Information/Guidances/UCM204959.pdf. Accessed July 18, 2016.
23. Launay-Vacher V, Chatelut E, Lichtman SM, Wildiers H, Steer C, Aapro M. Renal insufficiency in elderly cancer patients: International Society of Geriatric Oncology clinical practice recommendations. Ann Oncol. 2007;18(8):1314-1321.

24. Launay-Vacher V, Oudard S, Janus N, et al. Prevalence of Renal Insufficiency in cancer patients and implications for anticancer drug management: the renal insufficiency and anticancer medications (IRMA) study. Cancer. 2007;110(6):1376-1384.

25. Dharnidharka VR, Kwon C, Stevens G. Serum cystatin C is superior to serum creatinine as a marker of kidney function: a meta-analysis. Am J Kidney Dis. 2002;40(2):221-226.

26. Brenner BM, Meyer TW, Hostetter TH. Dietary protein intake and the progressive nature of kidney disease: the role of hemodynamically mediated glomerular injury in the pathogenesis of progressive glomerular sclerosis in aging, renal ablation, and intrinsic renal disease. N Engl J Med. 1982;307(11):652-659.

27. Coresh J, Selvin E, Stevens LA, et al. Prevalence of chronic kidney disease in the United States. JAMA. 2007;298(17):2038-2047.

28. Weinstein JR, Anderson S. The aging kidney: physiological changes. Adv Chronic Kidney Dis. 2010;17(4):302-307.

29. Berger NA, Savvides P, Koroukian SM, et al. Cancer in the elderly. Trans Am Clin ClimatolAssoc. 2006;117:147-155; discussion 155-146.

30. de Barros Pontes L, Antunes YP, Bugano DD, Karnakis T, Giglio AD, Kaliks RA. Prevalence of renal insufficiency in elderly cancer patients in a tertiary cancer center. Einstein (Sao Paulo). 2014;12(3):300-303.

31. Launay-Vacher V, Spano JP, Janus N, et al. Renal insufficiency and anticancer drugs in elderly cancer patients: a subgroup analysis of the IRMA study. Crit Rev Oncol Hematol. 2009;70(2):124-133.

32. Arellano J, Hernandez RK, Wade SW, et al. Prevalence of renal impairment and use of nephrotoxic agents among patients with bone metastases from solid tumors in the United States. Cancer Med. 2015;4(5):713-720.

33. Bhaskaran K, Douglas I, Forbes H, dos-Santos-Silva I, Leon DA, Smeeth L. Body-mass index and risk of 22 specific cancers: a population-based cohort study of 5.24 million UK adults. Lancet. 2014;384(9945):755-765.

34. Aguilar EA, Ashraf H, Frontini M, Ruiz M, Reske TM, Cefalu C. An analysis of chronic kidney disease risk factors in a Louisiana nursing home population: a cross-sectional study. J La State Med Soc. 2013;165(5):260-263, 265-267.

35. Stengel B, Tarver-Carr ME, Powe NR, Eberhardt MS, Brancati FL. Lifestyle factors, obesity and the risk of chronic kidney disease. Epidemiology. 2003;14(4):479-487.

36. Yamagata K, Ishida K, Sairenchi T, et al. Risk factors for chronic kidney disease in a community-based population: a 10-year follow-up study. Kidney Int. 2007;71(2):159-166.

37. Lowrance WT, Ordonez J, Udaltsova N, Russo P, Go AS. CKD and the risk of incident cancer. J Am Soc Nephrol. 2014;25(10):2327-2334.

38. Butler AM, Olshan AF, Kshirsagar AV, et al. Cancer incidence among US Medicare ESRD patients receiving hemodialysis, 1996-2009. Am J Kidney Dis. 2015;65(5):763-772.

39. Birkeland SA, Lokkegaard H, Storm HH. Cancer risk in patients on dialysis and after renal transplantation. Lancet. 2000;355(9218):1886-1887.

40. Steenkamp R, Castledine C, Feest T. Chapter 6 Survival and causes of death of UK adult patients on renal replacement therapy in 2010: national and centre-specific analyses. Nephron Clin Pract. 2012;120(Suppl 1): c105-135.

41. Fischereder M. Cancer in patients on dialysis and after renal transplantation. Nephrol Dial Transplant. 2008;23(8):2457-2460.

42. Akchurin OM, Kaskel F. Update on inflammation in chronic kidney disease. Blood Purif. 2015;39(1-3):84-92.

43. Jorgensen L, Heuch I, Jenssen T, Jacobsen BK. Association of albuminuria and cancer incidence. J Am Soc Nephrol. 2008;19(5):992-998.

44. Wong G, Hayen A, Chapman JR, et al. Association of CKD and cancer risk in older people. J Am Soc Nephrol. 2009;20(6):1341-1350.

45. Christiansen CF, Johansen MB, Langeberg WJ, Fryzek JP, Sorensen HT. Incidence of acute kidney injury in cancer patients: a Danish population-based cohort study. Eur J Intern Med. 2011;22(4):399-406. 
46. Campbell GA, Hu D, Okusa MD. Acute kidney injury in the cancer patient. Adv Chronic Kidney Dis. 2014;21(1):64-71.

47. Wagrowska-Danilewicz M, Danilewicz M. Nephrotic syndrome and neoplasia: our experience and review of the literature. Pol J Pathol. 2011;62(1):12-18.

48. Davidson MB, Thakkar S, Hix JK, Bhandarkar ND, Wong A, Schreiber MJ. Pathophysiology, clinical consequences, and treatment of tumor lysis syndrome. Am J Med. 2004;116(8):546-554.

49. Seccareccia D. Cancer-related hypercalcemia. Can Fam Physician. 2010;56(3):244-246, e290-242. French.

50. Moreau P, San Miguel J, Ludwig H, et al. Multiple myeloma: ESMO Clinical Practice Guidelines for diagnosis, treatment and follow-up. Ann Oncol. 2013;24(Suppl 6):vi133-137.

51. Oyajobi BO. Multiple myeloma/hypercalcemia. Arthritis Res Ther 2007;9(Suppl 1):S4.

52. Goldschmidt H, Lannert H, Bommer J, Ho AD. Multiple myeloma and renal failure. Nephrol Dial Transplant. 2000;15(3):301-304.

53. Launay-Vacher V, Ayllon J, Janus N, et al. Drug management of prostate cancer: prevalence and consequences of renal insufficiency. Clin Genitourin Cancer. 2009;7(3):E83-89.

54. Launay-Vacher V, Etessami R, Janus N, et al. Lung cancer and renal insufficiency: prevalence and anticancer drug issues. Lung. 2009; 187(1):69-74.

55. Launay-Vacher V, Gligorov J, Le Tourneau C, et al. Prevalence of renal insufficiency in breast cancer patients and related pharmacological issues. Breast Cancer Res Treat. 2010;124(3):745-753.

56. Khafagy R, Shackley D, Samuel J, O’Flynn K, Betts C, Clarke N. Complications arising in the final year of life in men dying from advanced prostate cancer. J Palliat Med. 2007;10(3):705-711.

57. National Kidney Foundation. 2002. NKF KDOQI guidelines. Available from: http://www2.kidney.org/professionals/KDOQI/guidelines_ckd/ toc.htm. Accessed March 18, 2015.

58. Coleman R, Body JJ, Aapro M, Hadji P, Herrstedt J. Bone health in cancer patients: ESMO Clinical Practice Guidelines. Ann Oncol. 2014;25(Suppl 3):iii124-137.

59. Gralow JR, Biermann JS, Farooki A, et al. NCCN Task Force Report: bone health in cancer Care. J Natl Compr Canc Netw. 2013;11 (Suppl 3): S1-50; quiz S51.

60. Goldfarb S, McCullough PA, McDermott J, Gay SB. Contrast-induced acute kidney injury: specialty-specific protocols for interventional radiology, diagnostic computed tomography radiology, and interventional cardiology. Mayo Clin Proc. 2009;84(2):170-179.

61. Perazella MA. Gadolinium-contrast toxicity in patients with kidney disease: nephrotoxicity and nephrogenic systemic fibrosis. Curr Drug Saf. 2008;3(1):67-75.

62. Perazella MA, Moeckel GW. Nephrotoxicity from chemotherapeutic agents: clinical manifestations, pathobiology, and prevention/therapy. Semin Nephrol. 2010;30(6):570-581.

63. Miller RP, Tadagavadi RK, Ramesh G, Reeves WB. Mechanisms of cisplatin nephrotoxicity. Toxins (Basel). 2010;2(11):2490-2518.

64. Stewart DJ, Mikhael NZ, Nanji AA, et al. Renal and hepatic concentrations of platinum: relationship to cisplatin time, dose, and nephrotoxicity. J Clin Oncol. 1985;3(9):1251-1256.

65. Hensley ML, Hagerty KL, Kewalramani T, et al. American Society of Clinical Oncology 2008 clinical practice guideline update: use of chemotherapy and radiation therapy protectants. $J$ Clin Oncol. 2009;27(1):127-145.

66. Dekkers IA, Blijdorp K, Cransberg K, et al. Long-term nephrotoxicity in adult survivors of childhood cancer. Clin J Am Soc Nephrol. 2013;8(6):922-929.

67. Farry JK, Flombaum CD, Latcha S. Long term renal toxicity of ifosfamide in adult patients - 5 year data. Eur J Cancer. 2012;48(9):1326-1331.

68. Gilbar PJ, Richmond J, Wood J, Sullivan A. Syndrome of inappropriate antidiuretic hormone secretion induced by a single dose of oral cyclophosphamide. Ann Pharmacother. 2012;46(9):e23.

69. Widemann BC, Balis FM, Kempf-Bielack B, et al. High-dose methotrexate-induced nephrotoxicity in patients with osteosarcoma. Cancer 2004;100(10):2222-2232.
70. Rajkumar SV, Dimopoulos MA, Palumbo A, et al. International Myeloma Working Group updated criteria for the diagnosis of multiple myeloma. Lancet Oncol. 2014;15(12):e538-548.

71. Jolivot PA, Poinsignon V, Paci A, et al. A case of melphalan sustained accumulation in an 80-year old patient. Int $J$ Clin Pharm. 2015;37(6):984-987.

72. EMC+. Melphalan summary of product characteristics. 2014. Available from: https://www.medicines.org.uk/emc/medicine/703. Accessed October 1, 2015.

73. Bird JM, Fuge R, Sirohi B, et al. The clinical outcome and toxicity of high-dose chemotherapy and autologous stem cell transplantation in patients with myeloma or amyloid and severe renal impairment: a British Society of Blood and Marrow Transplantation study. $\mathrm{Br} J$ Haematol. 2006;134(4):385-390.

74. Hayman SR, Leung N, Grande JP, Garovic VD. VEGF inhibition, hypertension, and renal toxicity. Curr Oncol Rep. 2012;14(4): 285-294.

75. Zhu X, Wu S, Dahut WL, Parikh CR. Risks of proteinuria and hypertension with bevacizumab, an antibody against vascular endothelial growth factor: systematic review and meta-analysis. Am J Kidney Dis. 2007;49(2):186-193.

76. Crino L, Dansin E, Garrido P, et al. Safety and efficacy of first-line bevacizumab-based therapy in advanced non-squamous non-smallcell lung cancer (SAiL, MO19390): a phase 4 study. Lancet Oncol. 2010;11(8):733-740.

77. Peng L, Zhao Q, Ye X, Zhou Y, Hu D, Zheng S. Incidence and risk of proteinuria with aflibercept in cancer patients: a meta-analysis. PLoS One. 2014;9(11):e111839.

78. EMC+. Opdivo summary of product characteristics. 2016. Available from: https://www.medicines.org.uk/emc/medicine/30476. Accessed August 5, 2016.

79. EMC+. Keytruda summary of product characteristics. 2016. Available from: https://www.medicines.org.uk/emc/medicine/30602. Accessed August 5, 2016.

80. Lapi F, Azoulay L, Niazi MT, Yin H, Benayoun S, Suissa S. Androgen deprivation therapy and risk of acute kidney injury in patients with prostate cancer. JAMA. 2013;310(3):289-296.

81. Coleman RE. Clinical features of metastatic bone disease and risk of skeletal morbidity. Clin Cancer Res. 2006;12(20 Pt 2):6243s-6249s.

82. Body JJ, Diel IJ, Lichinitzer M, et al. Oral ibandronate reduces the risk of skeletal complications in breast cancer patients with metastatic bone disease: results from two randomised, placebo-controlled phase III studies. Br J Cancer. 2004;90(6):1133-1137.

83. Rosen LS, Gordon D, Tchekmedyian NS, et al. Long-term efficacy and safety of zoledronic acid in the treatment of skeletal metastases in patients with nonsmall cell lung carcinoma and other solid tumors: a randomized, Phase III, double-blind, placebo-controlled trial. Cancer. 2004;100(12):2613-2621.

84. Fizazi K, Carducci M, Smith M, et al. Denosumab versus zoledronic acid for treatment of bone metastases in men with castrationresistant prostate cancer: a randomised, double-blind study. Lancet. 2011;377(9768):813-822.

85. Fizazi K, Lipton A, Mariette X, et al. Randomized phase II trial of denosumab in patients with bone metastases from prostate cancer, breast cancer, or other neoplasms after intravenous bisphosphonates. J Clin Oncol. 2009;27(10):1564-1571.

86. Lipton A, Fizazi K, Stopeck AT, et al. Superiority of denosumab to zoledronic acid for prevention of skeletal-related events: a combined analysis of 3 pivotal, randomised, phase 3 trials. Eur $J$ Cancer 2012;48(16):3082-3092.

87. Lipton A, Steger GG, Figueroa J, et al. Extended efficacy and safety of denosumab in breast cancer patients with bone metastases not receiving prior bisphosphonate therapy. Clin Cancer Res. 2008;14(20):6690-6696.

88. Novartis. Zometa ${ }^{\circledR}$ Summary of Product Characteristics. 2006. Available from: http://www.ema.europa.eu/docs/en_GB/document_library/ EPAR_-_Product_Information/human/000336/WC500051730.pdf. Accessed September 18, 2016. 
89. Houston S, Grieve RJ, Hickish T, Percival F, Hamilton E. Renal function changes and NHS resource use in breast cancer patients with metastatic bone disease treated with IV zoledronic acid or oral ibandronic acid: a four-centre non-interventional study. JMed Econ. 2010;13(1):162-167.

90. Arellano J, Hauber AB, Mohamed AF, et al. Physicians' preferences for bone metastases drug therapy in the United States. Value Health. 2015;18(1):78-83.

91. Ltd. HU. Pamidronate disodium summary of product characteristics. Available from: https://www.medicines.org.uk/emc/medicine/21442 2014; http://www.accessdata.fda.gov/drugsatfda_docs/ label/2014/021113s017lbl.pdf. Accessed January 9, 2017.

92. Perazella MA, Markowitz GS. Bisphosphonate nephrotoxicity. Kidney Int. 2008;74(11):1385-1393.

93. Amgen. 2015. XGEVA Prescribing Information. Available from: http:// pi.amgen.com/united_states/xgeva/xgeva_pi.pdf. Accessed September $18,2015$.

94. Amgen. 2014. XGEVA Summary of Product Characteristics. Available from: http://www.ema.europa.eu/docs/en_GB/document_library/ EPAR_-_Product_Information/human/002173/WC500110381.pdf. Accessed September 18, 2015).

95. Tarloff JB , Lash LH. Toxicology of the Kidney. 3rd ed. Boca Raton, FL: CRC Press; 2004.

96. Lameire N. Nephrotoxicity of recent anti-cancer agents. Clin Kidney J. 2014;7(1):11-22.

97. Henry DH, Costa L, Goldwasser F, et al. Randomized, double-blind study of denosumab versus zoledronic acid in the treatment of bone metastases in patients with advanced cancer (excluding breast and prostate cancer) or multiple myeloma. J Clin Oncol. 2011;29(9):1125-1132.

98. Roche. Avastin Summary of Product Characterisitcs. Available from: http://www.ema.europa.eu/docs/en_GB/document_library/EPAR_-_ Product_Information/human/000582/WC500029271.pdf. Accessed September 21, 2015).

99. Astellas Pharma Europe B.V. Xtandi Summary of Product Characteristics. Available from: http://www.ema.europa.eu/docs/en_ GB/document_library/EPAR_-_Product_Information/human/002639/ WC500144996.pdf. Accessed September 21, 2015).

100. EMC+. Cisplatin summary of product characteristics. 2015. Available from: https:/www.medicines.org.uk/emc/medicine/623. Accessed September 21, 2015.

101. EMC+. Cyclophosphamide summary of product characteristics. 2014. Available from: https://www.medicines.org.uk/emc/medicine/29592. Accessed September 21, 2015).

102. EMC+. Ifosfamide summary of product characteristics. 2014. Available from: https://www.medicines.org.uk/emc/medicine/30183. Accessed September 21, 2015.

103. EMC+. Methotrexate summary of product characteristics. 2013. Available from: https://www.medicines.org.uk/emc/medicine/12034. Accessed September 21, 2015

104. Pfizer Ltd. Sunitinib summary of product characteristics. Available from: http://www.ema.europa.eu/docs/en_GB/document_library/ EPAR_-_Product_Information/human/000687/WC500057737.pdf. Accessed September 21, 2015.
105. EMC+. Gentamicin summary of product characteristics. 2015. Available from: https://www.medicines.org.uk/emc/medicine/21665. Accessed September 21, 2015.

106. EMC+. Tobramycin summary of product characteristics. 2015. Available from: https://www.medicines.org.uk/emc/medicine/6566. Accessed September, 212015.

107. Novartis Europharma Ltd. Votrient summary of product characteristics. Available from: http://www.ema.europa.eu/docs/en_GB/document_ library/EPAR_-_Product_Information/human/001141/WC500094272. pdf. Accessed September 21, 2015.

108. Benoit DD, Hoste EA. Acute kidney injury in critically ill patients with cancer. Crit Care Clin. 2010;26(1):151-179.

109. Salahudeen AK, Doshi SM, Pawar T, Nowshad G, Lahoti A, Shah P. Incidence rate, clinical correlates, and outcomes of AKI in patients admitted to a comprehensive cancer center. Clin J Am Soc Nephrol. 2013;8(3):347-354.

110. Mirrakhimov AE, Voore P, Khan M, Ali AM. Tumor lysis syndrome: a clinical review. World J Crit Care Med. 2015;4(2):130-138.

111. Ejaz AA, Pourafshar N, Mohandas R, Smallwood BA, Johnson RJ, Hsu JW. Uric acid and the prediction models of tumor lysis syndrome in AML. PLoS One. 2015;10(3):e0119497.

112. Wilson FP, Berns JS. Onco-nephrology: tumor lysis syndrome. Clin J Am Soc Nephrol. 2012;7(10):1730-1739.

113. Haragsim L, Dalal R, Bagga H, Bastani B. Ketorolac-induced acute renal failure and hyperkalemia: report of three cases. Am J Kidney Dis. 1994;24(4):578-580.

114. Whelton A. Nephrotoxicity of nonsteroidal anti-inflammatory drugs: physiologic foundations and clinical implications. Am J Med. 1999;106(5B):13S-24S.

115. Humphreys BD, Soiffer RJ, Magee CC. Renal failure associated with cancer and its treatment: an update. J Am Soc Nephrol. 2005;16(1): $151-161$.

116. Finkel KW, Howard SC. Onco-nephrology: an invitation to a new field. J Clin Oncol. 2014;32(22):2389-2390.

117. American Society of Nephrology. Onco-nephrology forum. 2016. Available from: https://www.asn-online.org/about/committees/committee.aspx?panel=OncoNeph. Accessed June 2, 2016.

118. University of Texas MD Anderson Cancer Center. Onco-nephrology fellowship. 2016. Available from: https://www.mdanderson.org/education-and-research/education-and-training/schools-and-programs/ graduate-medical-education/residency-and-fellowship-programs/ onco-nephrology-fellowship.html. Accessed June 2, 2016.

119. Abudayyeh AA, Lahoti A, Salahudeen AK. Onconephrology: the need and the emergence of a subspecialty in nephrology. Kidney Int. 2014;85(5):1002-1004.

120. EMC+. Zytiga summary of product characteristics. 2016. Available from: https://www.medicines.org.uk/emc/medicine/24976. Accessed May 5, 2016.

121. EMC+. Inlyta summary of product characteristics. 2016. Available from: https://www.medicines.org.uk/emc/medicine/27051. Accessed May 5, 2016.
Cancer Management and Research

\section{Publish your work in this journal}

Cancer Management and Research is an international, peer-reviewed open access journal focusing on cancer research and the optimal use of preventative and integrated treatment interventions to achieve improved outcomes, enhanced survival and quality of life for the cancer patient. The manuscript management system is completely online and includes

\section{Dovepress}

a very quick and fair peer-review system, which is all easy to use. Visit http://www.dovepress.com/testimonials.php to read real quotes from published authors. 